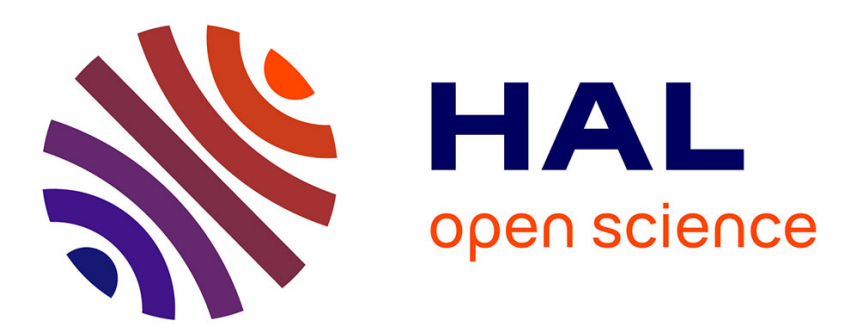

\title{
Dealing with a positive result: routine HIV testing among pregnant women in Vietnam
}

Pauline Oosterhoff, Anita Petra Hardon, Thu Anh Nguyen, Ngocyen Pham, Pamela Wright

\section{- To cite this version:}

Pauline Oosterhoff, Anita Petra Hardon, Thu Anh Nguyen, Ngocyen Pham, Pamela Wright. Dealing with a positive result: routine HIV testing among pregnant women in Vietnam. AIDS Care, 2008, 20 (06), pp.654-659. 10.1080/09540120701687026 . hal-00513431

\section{HAL Id: hal-00513431 https://hal.science/hal-00513431}

Submitted on 1 Sep 2010

HAL is a multi-disciplinary open access archive for the deposit and dissemination of scientific research documents, whether they are published or not. The documents may come from teaching and research institutions in France or abroad, or from public or private research centers.
L'archive ouverte pluridisciplinaire HAL, est destinée au dépôt et à la diffusion de documents scientifiques de niveau recherche, publiés ou non, émanant des établissements d'enseignement et de recherche français ou étrangers, des laboratoires publics ou privés. 

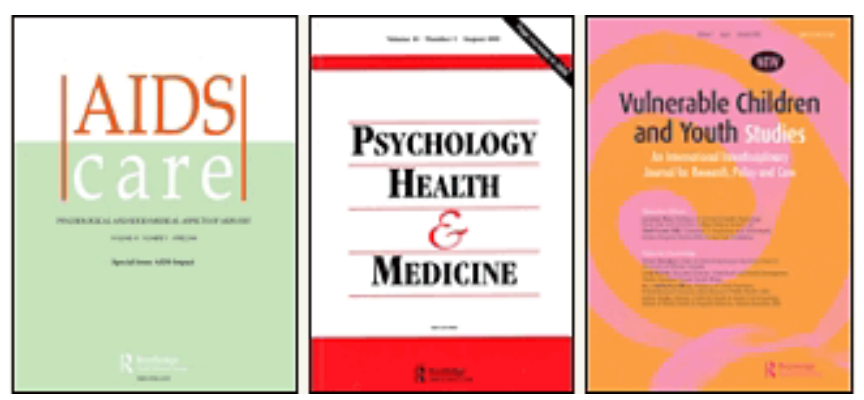

\section{Dealing with a positive result: routine HIV testing among pregnant women in Vietnam}

\begin{tabular}{|r|l|}
\hline Journal: & $\begin{array}{l}\text { AIDS Care - Psychology, Health \& Medicine - Vulnerable Children } \\
\text { and Youth Studies }\end{array}$ \\
\hline Manuscript ID: & AC-2007-02-0057.R2 \\
\hline Journal Selection: & AIDS Care \\
\hline Keywords: & Vietnam, Routine testing, VCT, PMTCT, Stigma \\
\hline \multicolumn{2}{|c}{} \\
\hline
\end{tabular}

\section{s ScholarONE" \\ Manuscript Central}




\section{Dealing with a positive result: routine HIV testing of pregnant women in Vietnam}

Introduction

Prevention of mother to child transmission (PMTCT) is a strategically important intervention to slow the spread of HIV/AIDS. In Vietnam the national prevalence of HIV was estimated at $0.5 \%$ in 2005. The epidemic is concentrated among young male intravenous drug users ( $\mathrm{MOH} 2006 \mathrm{~b})$, $50 \%$ of them between the ages of 20-29 (Nguyen Tran Hien 2007).

This study was conducted in Hanoi, in the North of Vietnam, where rapid economic growth and easily available heroin are associated with increased intravenous drug use. HIV prevalence among male intravenous drug users is $20-70 \%(\mathrm{MOH} 2006 \mathrm{a}$, Tung ND et al. 2001, Hien NT et al. 2001, Hien NT et al. 2000), with a rate among female commercial sex workers of $6.5 \%$ in 2005 (Socialist Republic of Vietnam 2005; Tran et al. 2005). The prevalence rate among pregnant women increased from $0.02 \%$ in 1994 to $0.37 \%$ in 2005 (MOH 2006a; $\mathrm{MOH}$ \& Department of Health Legislation 2006) and is as high as $1.25 \%$ in Hanoi. Pregnant women found to be HIV positive often face stigmatization as a possible sex-worker or drug user (Khuat T.H, et al. 2004).

In Vietnam, pregnant women can be tested at ante-natal care (ANC) facilities or at voluntary counseling and testing (VCT) sites (by 2006 there were around 50 VCT sites in the country, National Committee for AIDS, Drugs, Prostitution Control \& Health 2006). The new HIV/AIDS law (January 2007) legalizes a system of voluntary, routine and compulsory HIV testing (the latter in circumstances as yet undefined, Socialist Republic of Vietnam 2006). Government health facilities have held responsibility for HIV testing among people at risk since 1995 (AIDS ordinance $31 / 5 / 1995)$. 
The World Health Organization (WHO) and the US Centers for Disease Control and Prevention promote routine testing for HIV, now that accessibility to anti-retroviral medication is increasing. They recommend that such routine testing should be accompanied with a clear 'opt-out' procedure (WHO 2007, CDC 2006). As HIV programs scale up, documentation is needed on how opt-out and VCT models work in practice. This qualitative study examines how (pregnant) women, their families, and health providers, experienced VCT, routine HIV testing, disclosure and notification in the Hanoi health system. This setting could be described as low HIV prevalence, with high ANC coverage.

Currently, HIV tests are routinely offered to pregnant women in hospital before delivery and through ANC services in district health centers. In ANC sites, HIV tests are one of a set of tests conducted - others include blood count, blood type, blood sugar, hepatitis B, and syphilis. These test are done when women are 7-8 months pregnant. When an HIV test is positive, health workers at district or commune are asked to inform the HIV-positive women in their homes. But despite such routine testing in ANC sites and delivery services, few women seem to be detected by this system: In 2005, just 659 pregnant women were reported to be HIV-positive in the whole country, while the number expected from surveillance data was 7,000-8,000. (National Committee for AIDS, Drugs, Prostitution Control \& Ministry of Health 2006; Socialist Republic of Vietnam December 2005). One reason for such underreporting may be that HIV testing is not available at commune health centers. Women who use the commune health center for both ANC and delivery will not be tested.

\section{Respondents and Methods}

We used semi-structured question guides to interview a convenience sample of 38 seropositive women in Hanoi. Thirty-six women had recently delivered. Because HIV prevalence is low, and interviewing women just before or after receiving a positive result is practically and ethically difficult, the women were recruited from support groups and 
from national and provincial obstetric hospitals. Pregnant women identified as HIV positive at government facilities in Hanoi are increasingly referred to support groups, where they receive medical, social and economic support. The first interviews took place at the support group office outside the hospital, after the women had signed consent forms. HIV positive pregnant women who terminate their pregnancy may be more likely to keep their status secret, and less likely to join support groups: they are underrepresented in our sample. The sample included two women who had had an abortion after receiving a positive test result at a VCT center. All the other respondents were young mothers who had delivered within the last 30 months.

The topics covered in our interviews were experience with and views on ANC, VCT, routine opt-out and mandatory HIV tests, counseling, disclosure, social-economic support, care and health. Partners or a relative of 33 of the women were interviewed separately. The other women did not have partners or family members willing to be interviewed.

The women and their partners came from a variety of social and economic backgrounds. Most (32/38) were 20-30 years old; five women were 30-35 and one was over 40. Only two had a reported history of sex work and injecting drug use. In contrast, all of the partners had a reported history of intravenous drug use, visits to sex workers, or both. Six of the women were AIDS widows. Four women had been to university and all but two had completed a high school education.

Our respondents had learned about their HIV positive status in the following ways: 
- Through the notification systems, after testing in ANC:

18 women

- At a VCT center attended after husband or child was found to be HIV+:

19 women

- Through mandatory testing at rehabilitation center

1 woman

We also conducted semi-structured interviews with 53 healthcare workers on the quality and quantity of PMTCT services in Hanoi, using a multi-stage sampling frame.

- Health workers at all national and provincial hospitals in Hanoi providing PMTCT or antiretroviral therapy (ART) at the time of our study (2005/6) were selected; all provide VCT and routine HIV testing before deliveries. The sites included were the National Obstetric Hospital, Hanoi Obstetric Hospital, Bachmai hospital, Dongda Hospital, and the National Pediatric Hospital. At these hospitals, we visited the VCT facilities and ANC departments, and interviewed the department heads and at least one other health worker.

- To interview health workers at the district and commune level of health care, we selected the district with the highest HIV prevalence in the country, Dongda, where we interviewed health workers in all district health facilities that provide HIV testing, ANC or maternity services. We selected four communes (out of a total of 21 ) with the highest HIV prevalence and interviewed the heads of the commune health centers. At this level, the heads also treat patients but testing is not doen.

Inclusion criterion for interviewing the health workers at all levels was that they had been working at the facility for at least one year.

\section{Acceptability of offering routine and mandatory tests for pregnant women}

Eighteen of the women learned they were HIV+ after routine testing at ANC facilities, which is usually done at 7-8 months of pregnancy. The pregnant women perceived the offering of routine HIV tests during ANC as reasonable. Frequently heard comments from women and their families included:

"HIV tests are just like other tests." 
"They need to know that to help me."

"Doctors need to be able to protect themselves during their work."

The interviewed women saw no differences in principle between an HIV test and other medical tests, like that for hepatitis B.

We found that when women come to a hospital for delivery they are routine tested for HIV, and not told that they can refuse: testing is mandatory. The only hospital that does have an opt-out procedure for women, who come for delivery, is the National Obstetric Hospital. Many women explicitly stated that mandatory testing prior to delivery is acceptable because of the association of HIV with socially stigmatizing behavior. They argued that women do not want to have to ask for an HIV test because that might suggest that they had socially unacceptable behavior. They said:

"HIV tests should just be more normal."

"All women should be tested, not just a few based on their or their husbands' appearance (as a drug user - authors)."

"I would be afraid to ask for an HIV test, because the doctors might think something."

All 38 women stressed the importance of HIV testing during pregnancy for having healthy children, but the thought that the timing of the tests was too late in the pregnancy.

"I would not have had a child if I had known that I was positive."

"I would not have taken that risk myself." 
A few of them commented that if the tests were voluntary, some patients might decline them to save money (a user-fee has to be paid for the tests).

\section{Acceptability of routine and mandatory tests to health staff}

The health workers interviewed were unanimously in favor of routine HIV testing. They stressed the importance of testing for PMTCT:

"It is easier for us to prevent transmission if we know who among the patients is infected with HIV"

"We need to know who is infected with HIV in order to help them get treatment."

Only a few health care workers mentioned that patients needed counseling. They did not see counseling as a way to enable women to decide for themselves whether or not they wanted a test. As one health worker said:

"Women should know what is included in an ANC check up, and how many tests they will have and why."

Health workers at district level and below liked routine testing at seven months' gestation because it protects them from having to deliver babies in HIV+ positive women: they are referred to provincial and national hospitals. Without prompting, staff expressed greater worries about hepatitis B than HIV, because hepatitis B is more contagious, and because they cannot refer pregnant women with hepatitis B to national and provincial hospitals.

Health workers at all levels also pointed out the normalizing effect of routine testing (as a standard set of blood tests) in an environment where HIV is socially stigmatized. 
"I am afraid to offer people HIV tests because they might get angry at me and think I am judging them."

Some health workers mentioned that in "suspicious" cases they would not want to wait for the routine tests late in pregnancy, due to concern over their own and the woman's health. Reasons for suspicion were: looking like a drug user, being accompanied by somebody who looked like a drug user, having certain jobs, such as "hotel work", being married to "drivers", simply "looking bad", or medical symptoms such as opportunistic infections or very low weight.

Six health workers in one hospital and two in the ANC clinic mentioned that they had conducted blood tests on patients without informing them:

'We only tell them we're taking a blood test, because if we say 'HIV test,' they refuse to take the test...."

All health staff argued in favor of offering HIV testing for free. They mentioned technical and economic restrictions to offering HIV testing earlier in the pregnancy.

"The results could change during the pregnancy, which could be dangerous for the woman's health at the time of delivery. If we do separate or repeat tests early and late in pregnancy it is very expensive." 


\section{Acceptability of VCT}

The 19 women who went to VCT centers after their husband or child became sick considered VCT a very important service for people who want to know their status. Three of these women went for VCT early in pregnancy, while two opted for abortion when the test was positive.All 18 women who had initially found out they were HIV positive through routine testing subsequently also visited a free VCT site in order to confirm the result.

"I just could not believe that I was positive. I went three times. After I kept getting the same result I had to believe it."

"I know that my child must have received the virus from me. But I went for testing to be sure and to learn more about the disease."

All the health workers considered VCT primarily an intervention targeting drug users and sex workers. They stress that VCT cannot replace routine testing during ANC.

\section{Two parallel systems of counselling: counselling in the hospital and through notification}

Pregnant women tested at VCT centers and national sites receive their results there. Those who are tested during ANC at provincial or district level are not only supposed to be informed about their test results in the facilities; they also receive their test results at home through the 'notification' system. All commune and district government health facilities in Hanoi have to notify the provincial authorities of suspected HIV+ cases. After confirmation, the provincial authorities inform the local health workers at the district and commune levels, who then inform the patient and her/his family.

Fourteen of the 18 women who were tested at an ANC site, received their results from a health worker through the notification system in their community (see Table 1). 
Table 1 here.

In all cases of mandatory testing prior to delivery, women reported that one or several visiting family members were informed while the woman was still in hospital, without the woman's consent. Five women were, in fact, not informed about their status at all at this stage. Three of them said that they understood the staff's decision not to disclose the HIV+ result to them. They emphasized that both their families and the health staff probably "wanted to protect" them. Two of these non-informed women objected. One was told at the delivery table that she was positive:

"They gave my husband counseling but he did not tell me because he was afraid that I was too weak at that time. That's why I breastfed my son until my husband told me the truth after two months." Her son died of AIDS.

Family members reported that they did not feel prepared to inform their daughters-in-law. One said,"l just could not bring myself to tell my sister in law that she was positive. Her husband had just died."

Health care workers at routine testing sites did not have to use the community notification system to inform their clients of their status, but found it difficult to inform and counsel patients about a positive HIV test result. They gave various reasons for avoiding informing women directly about their status. Some mentioned "the weak health" of the women. Being "too busy" to inform all patients because "staff has to focus on the delivery" was mentioned several times by both patients and health staff as a reason for staff not informing the patient.

District and commune health workers stressed the public health benefits of the community notification system for both the community and the individual. But, women complained about breaches of confidentiality when the commune health workers come to inform them about their status and counsel them in their homes: 
"Whenever they visited my home, they still wore their white coats; that is unusual so it attracted attention from neighbors which is not good. I prefer to visit the clinics myself and only when somebody is really sick."

They also complain that the quality of counseling is poor. One woman was told not to eat at local food stalls and not to have her hair washed at a local salon, and she was warned by health staff not to sell food or drinks. Another woman was told to use formula feeding for her infant, which she could not afford.

Several interviewees described adverse mental health effects from the public disclosure of their HIV status:

"I just lay in bed for three months after they came to the door."

"My husband became depressed and escaped into drugs."

After notification by a commune healthcare worker, many young mothers say, that people treat them and their husbands and children in a different way. Almost all families introduced some segregation for both husband and wife after notification. For example, they and their partners could no longer eat at the same table, or share dishes or share the toilet; a few were thrown out of the house. Several women described feeling insecure about their own or their children's future in the household.

"My mother-in-law likes my sister-in-law's baby more than my son. When the two children play together, she always wants to separate my son. She beats my son. She already told us that when we die our son has to go to an orphanage." 
Others described losing jobs after notification. A hairdresser who worked at the market was unemployed because:

"Somebody who works in the market saw the health workers at my in-laws' house to counsel my in-laws while I was at the market. My husband died and my in-laws do not pay for my food but I cannot work in the market anymore because now everybody knows."

Some of our respondents said they tried to avoid notification, by giving the wrong address at the ANC site. One couple, of which the woman had tested positive during ANC at the provincial level, moved house immediately after they found out from the support group members about the notification procedure and the associated lack of confidentiality.

\section{Discussion}

The women in this study comprise two groups - women who see themselves at risk and go for VCT where their test results are treated confidentially; and women who are not aware of their risk, are detected at ANC sites and are notified in their community. Our findings suggest that both health care workers and patients agree on the medical importance of offering the tests as a provider-initiated routine procedure in health facilities. They appreciate the fact that this approach allows them to avoid having to discuss testing for a stigmatizing disease. However, the HIV positive women who are informed about their test results by commune health workers through the community notification system report that they feel stigmatized because their privacy is not respected. 
Worldwide, increased access to anti-retroviral medications has led to policies that promote routine provider-initiated testing with opt-out procedures (WHO/UDNAIDS 2007, CDC September 2006; Bayer R \& Fairchild A L 2006; Gayatri C et al. 2003; Weiser SD et al. 2006; Simpson et al. 1999; Walmsley S 2003). The introduction of rapid tests enable this trend: health systems no longer need complex confirmation procedures that act as barriers to counseling, and lead to delays in notification and loss to follow-up (Bramson BM 2003).

HIV prevalence is relatively low in Vietnam; the average pregnant woman has a low risk of testing $\mathrm{HIV}_{+}$, but our findings suggest that a "positive" result can have very serious social and health consequences. The quality of post-test counseling in the hospitals and district levels of health care is currently not good enough. Post-test counseling can moreover only be conducted when the results of the HIV tests are confirmed. Rapid tests are not yet used in Hanoi. When positive results are received from the confirmation centers, health workers are uncomfortable about informing women. This reflects their lack of communication skills and technical knowledge, but also the cultural values of saving face and showing care by protecting people from bad news. Technical knowledge may be improved quickly by training, and the introduction of rapid tests can facilitate the process, but these powerful cultural norms are unlikely to change rapidly. Programs that train health workers in the various PMTCT options, make them more sensitive to the reproductive rights of women, and improve their counseling skills are urgently needed. Such programs need to be sensitive to the Vietnamese cultural tendency to avoid talking about a stigmatizing disease, but should also provide acceptable approaches for informing women of their HIV+ status.

HIV + women were found to go for repeat tests often, to confirm their status and receive additional counseling. A combined system of routine testing in ANC with appropriate post-test counseling and opt-out and confidentiality procedures, along with good quality and accessible VCT is needed to meet this demand and increase uptake of testing in pregnancy. The health authorities in Vietnam also need to consider expanding the routine testing in ANC to the commune level of 
health care, using simple rapid test kits - this would remove the need to inform HIV+ women of their status in their homes, and thereby significantly reduce the stigma that they face. Pregnant women, who are at risk (for example partners of intravenous drugs users), need to have access HIV tests early in pregnancy, when abortion is still possible. The health system should enable such early testing and ensure that these women at risk get the counseling they need to make their own reproductive choices. 


\section{References}

AIDS ordinance. (31/5/1995). (Vol. Section 2 Chapter 2 art 16).

Bayer, R., \& Fairchild, A.L. (2006). Changing the paradigm for HIV testing - The end of exceptionalism. The New England Journal of Medicine, 355 (7), 647-649.

Branson, B.M. (2003). Point-of-care rapid tests for HIV antibodies. Laboratoriumsmedizin, 27 (7), 288-295.

CDC. (2006). Revised recommendations for HIV testing of adults, adolescents and pregnant women in health-care settings. Centres for Disease Control and Prevention. Atlanta, September 2006.

Hien, N.T., Giang, L.T., Binh, P.N., Devillé, W., van Ameijden, E.J.C., \& Wolffers, I. (2001). Risk factors of HIV infection and needle sharing among injecting drug users in Ho Chi Minh city, Vietnam. Journal of Substance Abuse, $13(1), 45-58$.

Hien, N.T., Giang, L.T., Binh, P.N., \& Wolffers, I. (2000). The social context of HIV risk behavior by drug injectors in Ho Chi Minh city, Vietnam. AIDS Care, 12 (4), 483-495.

Jayaraman, G.C., Preiksaitis, J.K., \& Larke, B. (2003). Mandatory reporting of HIV infection and opt-out prenatal screening for HIV infection: Effect on testing rates. Canadian Medical Association Journal, 168 (6), 679-682.

Khuat, T.H., Nguyen, T.V.A., \& Ogden, J. (2004). Understanding HIV and AIDS-related stigma and discrimination. Hanoi.

Ministry of Health. (2006a). Decision 214/2006/QD-TTg. Approval for the proposal "Manage vocational training and job advocacy for ex drug users in Hanoi". Vietnam.

Ministry of Health. (2006b). Five-year review workshop on HIVIAIDS prevention and control in 2001-2005 and action plan for 2006-2010, MOH, Vietnam.

Ministry of Health \& Department of Health Legislation. (2006). Law on HIV/AIDS Prevention and Control, MOH, Vietnam. 
National Committee for AIDS, Drug and Prostitution Control, \& Ministry of Health. (2006). Fiveyear review workshop on HIVIAIDS prevention and control in 2001-2005 and action plan for 2006-2010. In: 149/BC-BYT. Vietnam, Hanoi.

Nguyen, T.H. (2007). Situation of HIV/AIDS/STI surveillance in Vietnam. Presented at the National Conference on HIV/AIDS Monitoring and Evaluation, Hanoi.

Simpson, W.M., Johnstone, F.D., Goldberg, D.J., Gormley, S.M., \& Hart, G.J. (1999). Antenatal HIV testing: Assessment of a routine voluntary approach. British Medical Journal, 318, 1660-1661.

Socialist Republic of Vietnam. (2005). Second country report on following up the implementation to the Declaration of Commitment on HIV/AIDS January 2003 - December 2005. Hanoi, December 2005.

Socialist Republic of Vietnam. (2006). Law on HIV/AIDS prevention and control, MOH, Vietnam. Tran, T.N., Detels, R., Long, H.T., \& Lan, H.P. (2005). Drug use among female sex workers in Hanoi, Vietnam. Addiction, 100 (5), 619-625.

Tung, N.D., Tuan, N.A., Hien, N.T., Hoang, T.V., Thang, B.D., Chung, A.K.T., et al. (2001). Behavioural survey in Vietnam 2000. NASB, Family Health Interational.

Walmsley, S. (2003). Opt in or opt out: What is optimal for prenatal screening for HIV infection? Canadian Medical Association Journal, 168 (6), 707-708.

Weiser, S.D., Heisler, M., Leiter, K., Percy-de Korte, F., Tlou, S., et al. (2006). Routine HIV testing in Botswana: A population-based study on attitudes, practices, and human rights concerns. PLoS Medicine, vol 3 (7), e261.

WHO/UNAIDS. (2007). Guidance on provider-initiated HIV testing and counselling in health facilities. WHO, Geneva. 
Table 1. Modes of testing and counseling ( $N=37$ HIV positive women)

\begin{tabular}{|l|l|l|l|l|}
\hline Testing site & $\begin{array}{l}\text { Nr. of women who received } \\
\text { counseling at a health facility about } \\
\text { their test results }\end{array}$ & $\begin{array}{l}\text { Nr. of women informed about their } \\
\text { HIV status in their homes }\end{array}$ \\
\cline { 2 - 5 } & Yes & No & Yes & No \\
\hline VCT & 19 & 0 & 1 & 4 \\
\hline ANC & 13 & 5 & 14 & 18 \\
\hline
\end{tabular}

*One interviewee was not included in this table because she was first tested and counselled in a rehabilitation camp. 